\title{
Stress-induced cardiomyopathy after general anesthesia for total gastrectomy -A case report-
}

\author{
Jong Taek Park ${ }^{1}$, Jang Young Kim², Ye-Won Kim¹, Kwan-Hoon Choi ${ }^{1}$, Byoung Hark Park ${ }^{3}$, and Hyun \\ Kyo $\operatorname{Lim}^{1}$ \\ ${ }^{1}$ Department of Anesthesiology and Pain Medicine, ${ }^{2}$ Division of Cardiology, Yonsei Unversity Wonju College of Medicine, Wonju \\ ${ }^{3}$ Department of Anesthesiology and Pain Medicine, Pundang Jessaeng General Hospital, Seongnam, Korea
}

Stress-induced cardiomyopathy, which is also known as takotsubo cardiomyopathy, is a cardiac syndrome of a transient, reversible left ventricular dysfunction that is caused by emotional and/or physical stress and surgery. Its clinical manifestations are similar to those of myocardial ischemia without a coronary artery lesion. Stress-induced cardiomyopathy is more common in middle-aged women, and the prognosis is favorable. We report the case of a 50 -year-old female patient who underwent a total gastrectomy and developed stress-induced cardiomyopathy after surgery. (Korean J Anesthesiol 2010; 58: 299-303)

Key Words: Anesthesia, Cardiomyopathy, Stress.

Stress-induced cardiomyopathy is a deterioration of the myocardium function caused by emotional or physical stress that results in transient, reversible ventricular dysfunction $[1,2]$. Since Dote et al. first reported a clinical case in 1991 [3], there has been an increase in the number of clinical reports of this form of cardiomyopathy. This syndrome is also known as 'takotsubo cardiomyopathy,' 'apical ballooning syndrome,' or 'broken heart syndrome' because its electrocardiographic (ECG) changes and clinical manifestations are similar to those of a myocardial infarction while the coronary artery shows normal findings [4-6]. Moreover, the cardiac apex decreases in mobility while the basal segment shows hyperkinesis $[6,7]$. The precise pathophysiological mechanism of stressinduced cardiomyopathy has not been revealed. However, its development is linked to a range of psychological and physical stresses, and occurs frequently in women in the postmenopausal period [2,4-7].

Recent studies reported that stress-induced cardiomyopathy can occur during anesthesia or surgery [8-11] but no reports of this condition occurring after surgery. We report a case of stress-induced cardiomyopathy that developed after a total gastrectomy.

Received: June 26, 2009. Revised: 1st, July 28, 2009; 2nd, August 24, 2009. Accepted: September $24,2009$.

Corresponding author: Hyun Kyo Lim, M.D., Department of Anesthesiology and Pain Medicine, Yonsei Unversity Wonju College of Medicine, 162, Ilsan-dong, Wonju 220-701, Korea. Tel: 82-33-741-1536, Fax: 82-33-742-8198, E-mail: hyunkyolim@yonsei.ac.kr

(c) This is an open-access article distributed under the terms of the Creative Commons Attribution Non-Commercial License (http:// creativecommons.org/licenses/by-nc/3.0/), which permits unrestricted non-commercial use, distribution, and reproduction in any medium, provided the original work is properly cited. 


\section{Case Report}

A 50-year-old, $146 \mathrm{~cm}, 44 \mathrm{~kg}$, female patient was admitted to hospital under a diagnosis of stomach cancer. She had no abnormal medical history. The pre-operative chest x-ray revealed multiple small nodules on the right upper, right lower and left lower lobes, but the ECG, blood test, and other tests were in the normal range.

Pre-medication was not provided, and her blood pressure (BP) and heart rate (HR) after arriving in the operating room was $140 / 90 \mathrm{mmHg}$ and 70 beats/min, respectively. For the induction of anesthesia, remifentanil $0.1 \mu \mathrm{g} / \mathrm{kg} / \mathrm{min}$ was administered continuously and thiopental sodium $175 \mathrm{mg}$ was injected intravenously. Muscle relaxation was achieved with rocuronium $40 \mathrm{mg}$ after confirming the loss of consciousness, and endotracheal intubation was performed. Anesthesia was maintained with $\mathrm{O}_{2} 2 \mathrm{~L} / \mathrm{min}$, air $2 \mathrm{~L} / \mathrm{min}$, sevoflurane $1-2$ vol\%, and remifentanil $0.05-0.15 \mu \mathrm{g} / \mathrm{kg} / \mathrm{min}$. A $20-\mathrm{G}$ catheter was placed onto the right radial artery for continuous BP monitoring during surgery. Mechanical ventilation was maintained with a tidal volume $\left(\mathrm{V}_{\mathrm{T}}\right)$, respiratory rate $(\mathrm{RR})$ and partial pressure of end-tidal carbon dioxide $\left(\mathrm{P}_{\mathrm{ET}} \mathrm{CO}_{2}\right)$ of $400 \mathrm{ml}, 10 / \mathrm{min}$ and $30-33 \mathrm{mmHg}$, respectively. Her vital signs during surgery were maintained with a $\mathrm{BP}, \mathrm{HR}$ and oxygen saturation of pulse oximetry $\left(\mathrm{SpO}_{2}\right)$ of $100-130 / 50-70 \mathrm{mmHg}, 60-70$ beats $/ \mathrm{min}$ and $99-100 \%$, respectively. Intra-operative arterial blood gas analysis (ABGA) indicated a $\mathrm{pH}$, partial pressure of arterial oxygen $\left(\mathrm{PaO}_{2}\right)$ and partial pressure of arterial carbon dioxide $\left(\mathrm{PaCO}_{2}\right)$ of $7.43,168 \mathrm{mmHg}$ and $38.7 \mathrm{mmHg}$, respectively, and the results of the two subsequent ABGAs did not show any significant differences. The operation was uneventful, which took $6 \mathrm{hrs}$ for the procedure and $6 \mathrm{hrs}$ and $50 \mathrm{~min}$. for anesthesia. The total amount of fluids administered was 3,500 ml of Hartman's solution, while the urine output and blood loss were $880 \mathrm{ml}$ and $600 \mathrm{ml}$, respectively. Pyridostigmine $10 \mathrm{mg}$ and glycopyrrolate $0.2 \mathrm{mg}$ were administered for the reverse of muscle relaxation. The endotracheal tube was removed after confirming normal spontaneous respiration and consciousness.
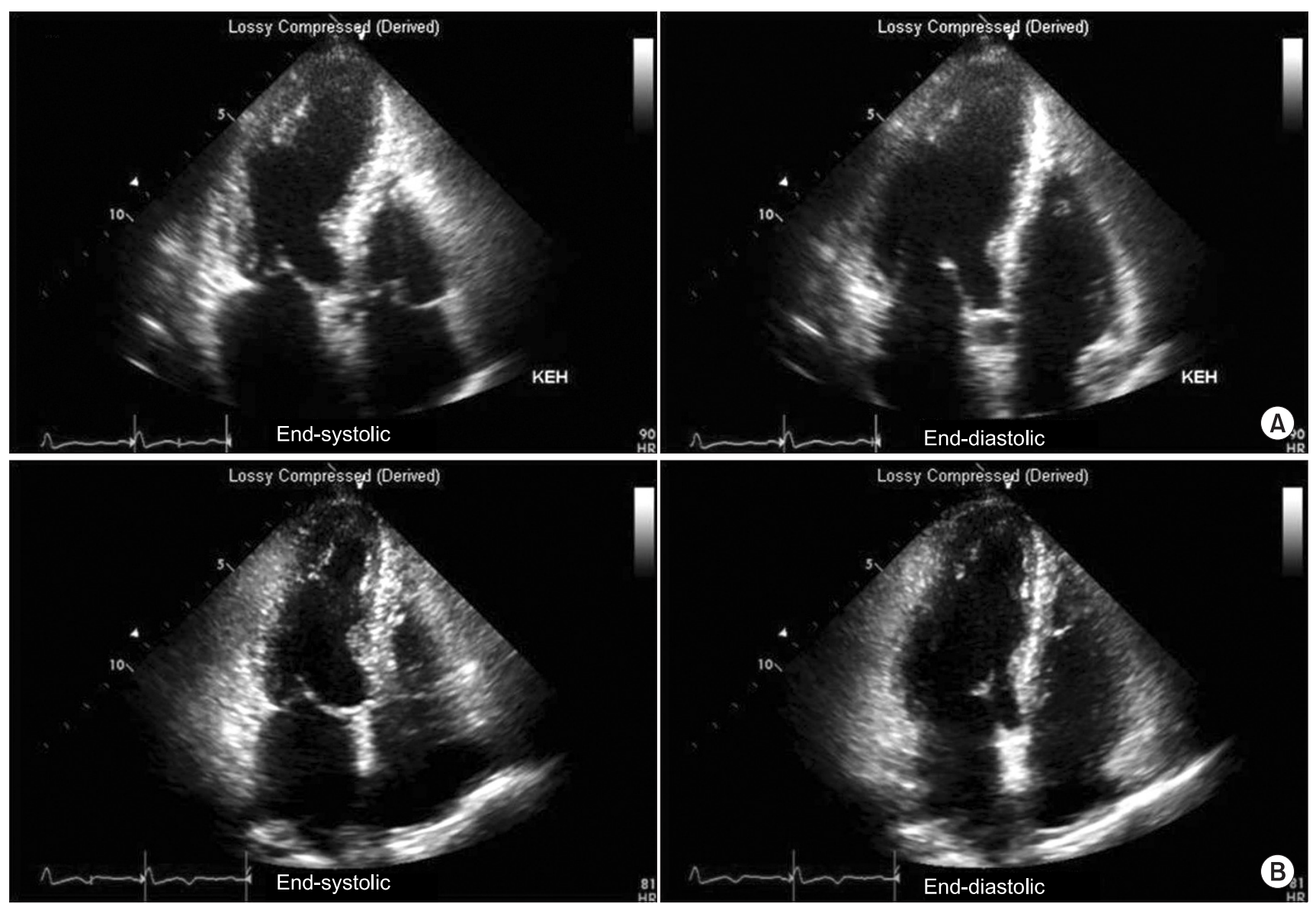

Fig. 1. Transthoracic echocardiography shows akinesia on all segments from the lower left ventricle to the apex (A). Follow-up echocardiography one month later shows a normal size with an improved global left ventricular systolic function (ejection fraction, $\mathrm{EF}=57 \rightarrow 68 \%$ ), and no regional wall motion abnormalities (B). 
The patient was transported to the post-anesthetic care unit (PACU), where she was oxygenated through a mask at $5 \mathrm{~L} / \mathrm{min}$ and her vital signs were maintained with a $\mathrm{SpO}_{2}, \mathrm{BP}$ and $\mathrm{HR}$ of $98 \%, 130-140 / 70-80 \mathrm{mmHg}$ and 70 beats/min, respectively. There were no abnormalities observed until she was transferred to the ward.

In the ward, $60 \mathrm{ml}$ of a mixed solution made from fentanyl 700 $\mu \mathrm{g}$, tramadol $400 \mathrm{mg}$, ondansetrone $12 \mathrm{mg}$ and a saline solution was administrated for post-operative pain control using IV PCA (patient-controlled analgesia) with a setting of infusion rate, bolus dose and lockout time of $0.5 \mathrm{ml}, 1 \mathrm{ml}$ and $15 \mathrm{~min}$, respectively. Every time the patient complained of pain, an additional $50 \mathrm{mg}$ of tramadol was provided by an intravenous bolus injection.

On post-operative day 2, a chest x-ray performed due to mild dyspnea revealed post-operative atelectasis in the left retrocardiac area. ABGA was performed with oxygenation at 10 $\mathrm{L} / \mathrm{min}$ with a reservoir mask. The results showed a $\mathrm{pH}, \mathrm{PaO}_{2}$ and $\mathrm{PaCO}_{2}$ of 7.45, $115 \mathrm{mmHg}$ and $35 \mathrm{mmHg}$, respectively, while $\mathrm{SpO}_{2}$ was maintained at $98 \%$. Therefore, she was monitored with blow therapy.

On the following day, the dyspnea persisted, so follow-up chest $\mathrm{x}$-ray was performed, the result of which revealed pleural effusion in both lung fields and mild cardiomegaly. ABGA indicated a $\mathrm{pH}, \mathrm{PaO}_{2}, \mathrm{PaCO}_{2}$ and $\mathrm{SpO}_{2}$ of 7.53, $92 \mathrm{mmHg}$, $35 \mathrm{mmHg}$ and $91-98 \%$, respectively, and ECG detected a T wave inversion in the V3-V5 leads. The cardiac biomarkers, such as CK-MB (creatine kinase-myocardial band) $1.93 \mathrm{ng} / \mathrm{ml}$ (normal value $<5.0 \mathrm{ng} / \mathrm{ml}$ ), Troponin-I $2.22 \mathrm{ng} / \mathrm{ml}$ (normal value $<0.78 \mathrm{ng} / \mathrm{ml}$ ), and BNP (brain natriuretic peptide) $705 \mathrm{pg} / \mathrm{ml}$ (normal value $<100 \mathrm{pg} / \mathrm{ml}$ ), was also observed but no catecholamine was found in the blood and urine. Transthoracic echocardiography performed to evaluate the cardiogenic dyspnea on postoperative day 4 revealed akinesia in all segments from the lower mid portion to the apex of the left ventricle, whereas hyperkinesia was detected in the cardiac base. At that time, a left ventricular ejection fraction (EF) of $57 \%$, a systolic pressure of right ventricle of $48 \mathrm{mmHg}$ and moderate pulmonary hypertension were observed (Fig. 1A). Stressinduced cardiomyopathy was suspected based on the ECG and echocardiography findings but the vital signs were maintained at BP and HR of 130/80 $\mathrm{mmHg}$ and 90 beats/min, respectively, and there were no other symptoms except for mild dyspnea. So the patient is monitored with oxygen therapy without any other treatment. On post-operative day 6, her vital signs were stable and no findings of respiratory disturbance were observed. The ECG showed a T wave inversion in V2-V6 (Fig. 2A) and the chest $x$-ray revealed lung congestion and cardiomegaly as well as atelectasis in the left lung. Analysis of the cardiac enzymes revealed the following: CK-MB $1.75 \mathrm{ng} / \mathrm{ml}$; Troponin-I $0.79 \mathrm{ng} / \mathrm{ml}$; BNP 1,219.8 pg/ml. Coronary angiography was recommended but the patient refused. On post-operative day 15 , she was discharged home under outpatient follow-up.

Two weeks after discharge, the outpatient follow-up did not reveal any abnormalities. Although $\mathrm{T}$ wave inversion was present in the $\mathrm{V} 1-\mathrm{V} 6$ leads on ECG, the ventricular wall motion was restored in all segments from the lower mid portion of the left ventricle to the apex. The left ventricular EF was increased to $68 \%$ while the systolic pressure of the right ventricle had decreased to $21 \mathrm{mmHg}$ (Fig. 1B). Nine months later, ECG showed no evidence of the disorder (Fig. 2B).

\section{Discussion}

Stress-induced cardiomyopathy is a reversible form of myocardiopathy that is likely triggered by physical or psychological stress or surgery. This syndrome occurs frequently in post-menopausal women mostly over the age of 50, but its precise prevalence is unknown. The incidence has been estimated to be approximately $2 \%$ of suspected cases of acute
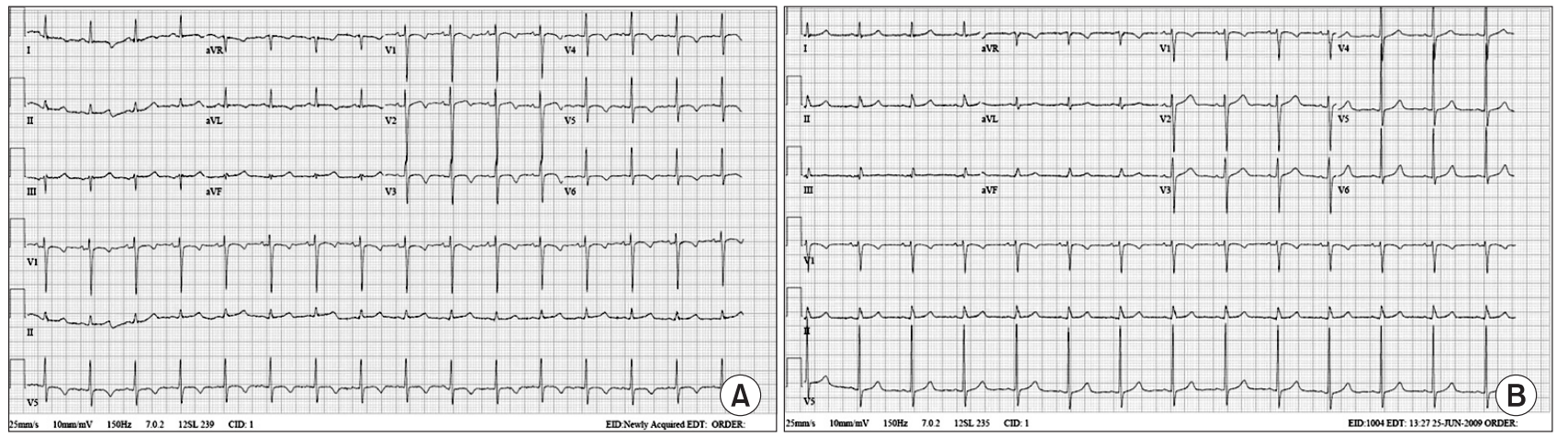

Fig. 2. 12-lead electrocardiography (ECG) performed 6 days after surgery showed a sinus rhythm with a T wave inversion in the V2 to V6 leads. Prolonged QTs were present in all leads (A). At the 9 month follow-up, ECG showed a restored normal sinus rhythm (B). 
myocardial infarction or patients showing ECG abnormalities of a $\mathrm{T}$ wave inversion $[1,2,5]$. The precise etiology is not completely understood. However, the most likely mechanisms are sympathetic hyperactivity related to stress and myocardial stunning due to an increase in the catecholamine level $[4,6,12]$. Approximately $70 \%$ of acute stress-induced cardiomyopathy patients show sympathetic hyperactivity and an increase in catecholamine [4].

The main clinical symptoms of this syndrome are chest pain or dyspnea, and a large number of patients had previously been exposed to emotional, physical, or surgical stress before the event $[1,2,5]$. In the present case, the mechanism of stress-induced cardiomyopathy is unclear, but its incidence appears to be linked to the anesthesia without any preanesthetic medication, gastrectomy, post-operative pain, and excessive psychological or physical stress from the postoperative treatment outcome [1]. On ECG, there are STsegment elevations in the precordial leads or $\mathrm{T}$ wave inversion in all 12 leads, and prolonged Q-T interval, while a pathologic Q wave also is found in $40 \%$ of patients [5]. In addition, the cardiac enzyme reveals normal or slightly increased CK-MB and troponin-I levels compared to a myocardial infarction [1], whereas the catecholamine level of the acute phase is significantly higher than that in a myocardial infarction showing a deterioration of the myocardial function to a similar degree [4]. Echocardiography shows an abnormal ejection fraction of the left ventricle with apical akinesia or hypokinesia but basal hyperkinesia. Such wall motion abnormalities in the left ventricle can be attributed to the distribution of the sympathetic nervous system congested in the base rather than in the apex [4]. In addition, the region of such lesions does not correspond to the distribution of the coronary artery, while the coronary angiography findings show normal or mild coronary arterial disorders $[4,5]$. In this case, the patient complains only mild dyspnea since 2 days after surgery, so the symptom was considered to be caused by a postoperative atelectasis. However, the chest $\mathrm{x}$-ray and ECG findings indicated a cardiac disorder, and ECG revealed a $\mathrm{T}$ wave inversion in the $\mathrm{V} 3-\mathrm{V} 5$ precordial leads, followed by a slight increase in cardiac enzyme levels, whereas echocardiography showed akinesia of the apex and hyperkinesia of the base.

These findings indicated stress-induced cardiomyopathy. Cardiomyopathy occurring in the perioperative setting tends to occur during the intra-operative period. There are no reports of a post-operative incidence except for one case occurring 4 hours after electroconvulsive therapy (ECT) [9]. Therefore, attention should be paid to the development of cardiomyopathy after a procedure or operation.

To assist in the diagnosis of stress-induced cardiomyopathy, the proposed Mayo criteria suggested that all of the following
4 conditions be met: 1) transient akinesis of the left ventricular apical segments with wall-motion abnormalities extending beyond the coronary arterial distribution on echocardiography; 2) an absence of coronary disease; 3 ) abnormalities of the ST-segment or T wave on ECG; and 4) an absence of cerebrovascular disease, pheochromocytoma, or other myocarditis caused by virus, etc $[5,6]$. However, recent studies of the diagnosis of stress-induced cardiomyopathy caused by cerebrovascular disease reported normal angiography findings and significant motion abnormalities on echocardiography $[1,2]$. In addition, case studies of atypical stress-induced cardiomyopathy reported that it was accompanied by a right ventricular motion abnormality or mid ventricular akinesis with apical hyperkinesia, etc [4]. Gaibazzi et al. reported that in cases concomitant with coronary artery stenosis, a modification of the conventional criterion should include normal coronary angiography findings [12].

Such cases appear to have the same pathophysiological mechanism, clinical features and outcomes as conventional stress-induced cardiomyopathy. Therefore, it is essential to establish more universal standards. In the present case, the absence of coronary arterial disease was not confirmed by coronary angiography but the condition was diagnosed as stress-induced cardiomyopathy because the patient was female in the prevalent age range group and no history of abnormalities indicative of coronary arterial disease in the pre-operative tests. In addition, the post-operative findings of cardiac enzymes, ECG and echocardiography fitted the diagnostic criteria of stressinduced cardiomyopathy. The prognosis of stress-induced cardiomyopathy is relatively favorable and the present case also showed a favorable outcome after conservative treatment. This syndrome may be accompanied by complications of congestive heart failure and pulmonary edema in $3-46 \%$ of patients and its associated mortality is $1-8 \%$ [5]. Myocardial dysfunction on echocardiography may take several days or weeks to recover [5], the ECG findings may show favorable changes in 3-4 months [1], and most patients make a complete recovery $[1,2,5]$. There is no established treatment for stress-induced cardiomyopathy but conservative management has been applied empirically according to each symptom, followed by observation of the outcome $[2,4-6,12]$.

Compared to previous reports mostly of the intra-operative incidence, cases of sudden ECG changes indicating coronary arterial disease, as in our case, have difficulty in distinguishing the early phase of stress-induced cardiomyopathy from coronary arterial disease. Stress-induced cardiomyopathy must be considered in a differential diagnosis if females in the postmenopausal period are exposed to psychological and/or physical stress, or surgery, or if patients with a low potentiality of coronary arterial disease show significant left 
ventricular motion abnormalities. It should be noted that this syndrome can occur post-operatively and efforts for anesthetic management should be made to reduce the incidence of stressinduced cardiomyopathy by decreasing the patient's stress level through appropriate sedation and pain control during the perioperative period.

\section{References}

1. Prasad A, Lerman A, Rihal CS. Apical ballooning syndrome (TakoTsubo or stress cardiomyopathy): a mimic of acute myocardial infarction. Am Heart J 2008; 155: 408-17.

2. Gianni M, Dentali F, Grandi AM, Sumner G, Hiralal R, Lonn E. Apical ballooning syndrome or takotsubo cardiomyopathy: a systemic review. Eur Heart J 2006; 27: 1523-9.

3. Dote K, Sato H, Tateishi H, Uchida T, Ishihara M. Myocardial stunning due to simultaneous multivessel coronary spasms: a review of 5 cases. J Cardiol 1991; 21: 203-14.

4. Pilgrim TM, Wyss TR. Takotsubo cardiomyopathy or transient left ventricular apical ballooning syndrome: a systemic review. Int J Cardiol 2008; 124: 283-92.

5. Bybee KA, Kara T, Prasad A, Lerman A, Barsness GW, Wright RS, et al. Systemic review: transient left ventricular apical ballooning: a syndrome that mimics ST-segment elevation myocardial infarction.
Ann Intern Med 2004; 141: 858-65.

6. Akashi YJ, Goldstein DS, Barbaro G, Ueyama T. Takotsubo cardiomyopathy: a new form of acute, reversible heart failure. Circulation 2008; 118: 2754-62.

7. Ramaraj R, Sorrell VL, Marcus F, Alpert JS. Recently defined cardiomyopathies: a clinician's update. Am J Med 2008; 121: 67481.

8. Lentschener C, Vignaux O, Spaulding C, Bonnichon P, Legmann P, Ozier Y. Early postoperative tako-tsubo-like left ventricular dysfunction: transient left ventricular apical ballooning syndrome. Anesth Analg 2006; 103: 580-2.

9. Littlejohn FC, Syed O, Ornstein E, Connolly ES, Heyer EJ. Takotsubo cardiomyopathy associated with anesthesia: three case reports. Cases J 2008; 1: 227.

10. Consales G, Campiglia L, Michelagnoli G, Gallerani E, Rinaldi S, Delpace S, et al. Acute left ventricular dysfunction due to tako-tsubo syndrome after induction of general anesthesia. Minerva Anestesiol 2007; 73: 655-8.

11. Cho CK, Jung SM, Kim JY, Kwon HU, Kang PS. Stress induced cardiomyopathy after local epinephrine use: a case report. Korean J Anesthesiol 2008; 54: 581-4.

12. Gaibazzi N, Ugo F, Vignali L, Zoni A, Reverberi C, Gherli T. Takotsubo cardiomyopathy with coronary artery stenosis: a case-series challenging the original definition. Int J Cardiol 2009; 133: 205-12. 